\title{
Patients driving alternative medicine boom
}

W ith patients seeking more choice and control over their health care options, Canadian health providers and facilities may soon have little choice but to follow the lead of their American counterparts who, increasingly, are offering complementary and alternative medicines in hospitals and other facilities.

Yet, while advocates of such therapies argue that they pose no threat to traditional medicine, skeptics continue to say more evidence is needed before unconventional therapies should be allowed to make major in-roads on Canadian health care.

Such skeptics are found less and less often in United States hospitals, according to a recent survey conducted by the American Hospital Association (www .siib.org/news/2468-SIIB/version/default /part/AttachmentData/data/CAM\%20 Survey $\% 20$ FINAL.pdf). It found that $42 \%$ of 714 surveyed hospitals offered at least one complementary or alternative therapy in 2010, as compared with $27 \%$ just five years earlier. The most popular therapies included natural products $(17.7 \%)$, deep breathing exercises $(12.7 \%)$, meditation $(9.4 \%)$, chiropractic care $(8.6 \%)$, massage $(8.3 \%)$, yoga $(6.1 \%)$ and diet-based therapies (3.6\%), typically in an attempt to treat back or neck pain, joint pain or stiffness, and anxiety and depression.

But clinical effectiveness was not the main reason why American hospitals are offering those therapies, says Sita Ananth, director of knowledge services at the Samueli Institute, a nonprofit research group based in Alexandria, Virginia, which focuses on "complementary, alternative and integrative medicine, optimal healing environments, relationship-centered care, the role of the mind and lifestyle in healing, health care policy research, and military and veterans health research," and which conducted the study in conjunction with the American Hospital Association. "What we're see-

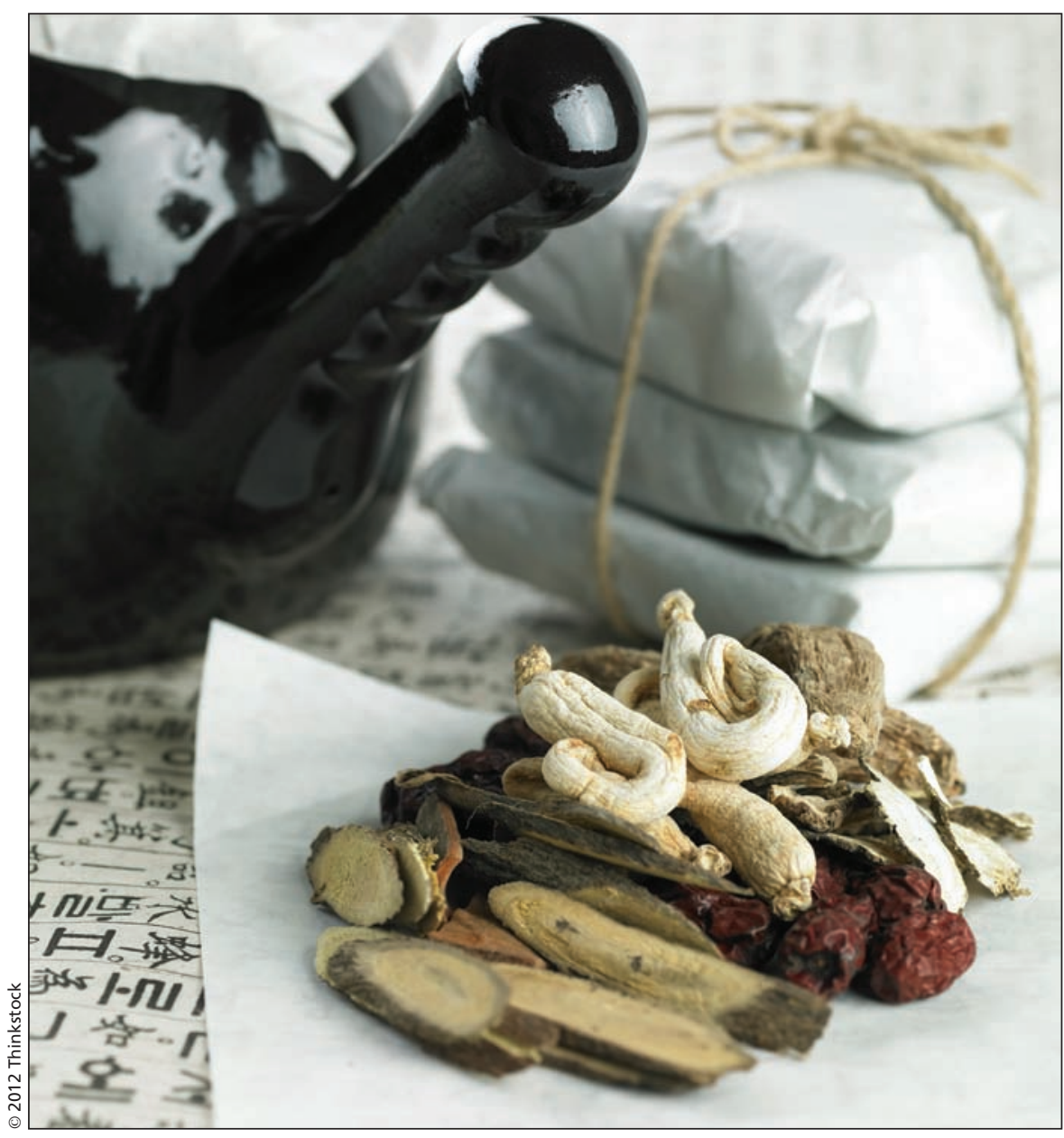

Research indicates that American health care providers seek out complementary and alternative therapies, such as naturopathic remedies, when dealing with their own health problems at a higher rate than the average American.

ing is that the patient demand is driving this movement in a big way."

That trend coincides with indications that American health care providers are themselves seeking out complementary and alternative therapies when dealing with their own health problems. In $2007,83 \%$ of American health care workers used complementary or alternative medicine, as compared with $63 \%$ of the general population (Health Serv Res 2012;47:211-27). They were also two times more likely to seek out practitioner-based complementary or alternative therapy and three times more likely to self-administer such therapy.

But while such therapy may no longer be "alternative" in the US, that's not the case in Canada, says Dr. Lloyd Oppel, an emergency physician in Vancouver, British Columbia who monitors alternative medicine on behalf of the BC Medical Association. "The walkaway message of a lot of these reports is that the public is rapidly adopting a New Age view to their health, and that's really not the case in Canada."

Indeed, Canadian hospitals don't offer such therapy to the same degree as their American counterparts, says Marja Verhoef, Canada Research Chair in Complementary Medicine at the University of Calgary in Alberta and cofounder of the Canadian Interdisci- 
plinary Network for Complementary \& Alternative Medicine Research. "There are some isolated hospitals that do some things but it's very limited. I don't think it will stay this way because the patient demands are definitely increasing."

But exactly how rapidly demand is rising remains unclear. A study conducted by the Fraser Institute indicated that over $54 \%$ of Canadians used a complementary or alternative therapy in 2006, an increase of $4 \%$ over 1997 , but it suggested the numbers may not capture all users and that the alternative therapies that were utilized included "prayer" and "relaxation techniques" (www.fraserinstitute.org/uploadedFiles /fraser-ca/Content/research-news/research /publications/complementary-alternative -medicine-in-canada-2007.pdf).

Nadeem Esmail, the study's author and director of health system performance for the institute, says that many users do not discuss use of such alternative therapies with their family physician.

That's in part because patients are seeking more personal control over their health care, says Dr. Badri Rickhi, director and founding member of the Canadian Institute of Natural and Integrative Medicine and clinical associate professor in the Department of Family Medicine at the University of Calgary. "The consumer is becoming much more aware and assertive in looking at responsibility for their health and often ends up educating their family physician about products."

Esmail says Canadians spent about $\$ 7.84$ billion on complementary and alternative medicine in 2006, as compared with $\$ 5.4$ billion in 1997 . The outlay included more than $\$ 5.6$ billion on providers and over $\$ 2.2$ billion on products such as herbs, vitamins, books and classes.

A parallel spending trend in the US is a good part of the reason that American hospitals are moving so rapidly to provide complementary and alternative therapies within their confines, Amanth says.

By contrast, Canadian facilities don't accede to patient demands in the same fashion because there isn't a financial incentive to do so, Oppel says. "In the US, they have a very different funding model. It's a more marketdriven environment. Patients will pay for just about anything."

Such Canadian reservations may be a good thing, skeptics say.

Alternative therapies can and should not be provided in Canadian hospitals until they've been scientifically proven to be effective, says Pamela Fralick, president and CEO of the Canadian Healthcare Association. But if "reliable research determines that a therapy is effective, then there would be no reason why we wouldn't support instituting it into hospitals."

Just because a patient wants an unscientific therapy isn't justification for providing it, adds Iain Martel, chair of the Committee for the Advancement of Scientific Skepticism, a body of the Centre for Inquiry Canada. "Patients read something on the Internet, they come in demanding these treatments, and there isn't strong scientific evidence for them. There are very, very few that turn out to have any value when they are properly studied."

Advocates counter that a bias toward Western medicine isn't justification for denying patients access to a therapy that could prove beneficial.

It's about improving quality of life for patients, says Dr. Aaron Michelfelder, a family practitioner in Maywood, Illinois, who has incorporated acupuncture and medical hypnosis into his practice at the Loyola University Medical Center.

Michelfelder says several of his patients have experienced improve- ments in their health after using alternative therapies. "Being a Western-trained physician, we are of course trained to be skeptical. So at first I was actually quite surprised at the results I was getting."

Dr. Richard Nahas, a former emergency physician and founder of the Seeker's Centre for Integrative Medicine in Ottawa, Ontario, concurs. "Although we discount it because it's nonscientific, human nature is such that in some cases personal experience is the most powerful type of evidence."

"There are a lot of problems that people face where the evidence-based approach isn't necessarily ideal," he adds, arguing that physicians should be more willing to explore treatment options in the interests of their patients, even if it undermines their own belief that medicine should be based on science. "What most doctors stand for is helping their patients get better. The problem is that if there's a lack of evidence, you're not supposed to try something new."

Alternative and complementary medicine doesn't need to be seen as a threat, Michelfelder says. "It's really about teamwork, the best approach to the patient, and using all the tools in the toolbox available. And I think the physician's job is to know about those options, make sure they are safe, and that the patient is not getting cheated."

But the true test of a therapy should be its efficacy, says Martel. "There's only medicine and if it works, and can be shown to work, then it gets incorporated."

The evidence is the evidence, whether it's a conventional or alternative therapy, Oppel says. "Go with the things that are shown to work and discard the ones that don't. Anything that is proven to work isn't alternative medicine." - Jordan Fallis, Ottawa, Ont.

CMAJ 2012. DOI:10.1503/cmaj.109-4151 